\title{
O ANIMAL NA ARTE CONTEMPORÂNEA SOB A PERSPECTIVA ECOFEMINISTA
}

\author{
Silvana Macêdo ${ }^{1}$
}

\begin{abstract}
RESUMO: Este artigo investiga a interação humana com outros animais e examina sua representação ou apresentação em projetos artísticos contemporâncos, considerando questões éticas envolvidas nesse processo. A perspectiva ccofeminista é proposta como uma ferramenta crítica para analisar trabalhos artísticos que lidem com o animal. Dentro dessa abordagem ecofeminista, são examinadas obras dos artistas: Joseph Beuys, Jannis Kounnellis, Wiliam Wegman e Beatriz da Costa. Ainda é considerada a vídeo-instalação sonora Cooperari, de Silvana e Frederico Macedo, produzida no contexto deste estudo.
\end{abstract}

PALAVRAS-CHAVE: ecofeminismo, arte contemporânea, animal.

\section{INTRODUÇÃO}

Há uma rica variedade de maneiras com que a temática do animal não-humano é abordada na arte contemporânea, estando muitas vezes associada à interface da arte com a ciência. Em termos de sua apresentação formal, animais são representados através de pinturas, fotografias, vídeos, entre outras mídias; ou apresentados mortos (empalhados) integrando instalações/esculturas; e ainda, são apresentados vivos como parte de performances e projetos "colaborativos".

\footnotetext{
' Programa de Pós-Graduação em Artes Visuais - PPGAV, CEAR'T, UDESC. Professora efetiva do Departamento de Artes Visuais, CEAR'l, UDESC.
} 
Além da interação com espécies existentes, a arte transgênica propõe a criação de novas espécies de animais através da manipulação genética. ${ }^{2}$

Sob o ponto de vista ético, há uma grande complexidade de questões que emergem dos procedimentos que envolvem o uso de animais na arte c, por esse motivo, parece-nos que não se pode abordar essa questão de maneira geral, simplista e normativa. Cada projeto apresenta suas particularidades e não nos parece produtivo avançar no sentido da elaboração de regras gerais proibitivas para a atuação artística. Portanto, parte-se da ideia de abordar a questão ética buscando uma perspectiva crítica capaz de nortear tanto a produção artística quanto servir de instrumento crítico na recepção de projetos que se relacionem com animais.

Entre os diversos debates teóricos atuais que examinam a relação humana com a natureza não-humana, concentramos este artigo na investigação da ética ecofeminista como uma possível perspectiva para elucidar o emaranhado de questões que envolvem o uso de animais em projetos de interface da arte, ciência e natureza.

Inicialmente, são levantados aspectos relevantes das discussões sobre o ccofeminismo, que serão posteriormente usados na análise de projetos artísticos específicos, nos quais a relação humana com o animal é uma questão central.

\section{ECOFEMINISMO}

O ecofeminismo surgiu na década de setenta a partir da mobilização de mulheres que uniram a luta da emancipação feminina às preocupações com problemas ambientais. O termo "ecofeminismo" foi originalmente cunhado pela escritora feminista francesa Françoise d'Eaubonne em seu livro Feminismo ou Morte (1974). De acordo com Carolyn Merchant, desde então as discussões em conferências e publicações ao longo das décadas de oitenta, noventa, até o presente, tornaram o ecofeminismo um forte movimento que trata da problemática da mulher e do meio ambiente (Merchant, 2005, p. 194-5).

\footnotetext{
2 Veja uma discussão sobre este assunto $\mathrm{cm}$ MACEDO, Silvana B. "O Animal na Interface da Arte com a Ciência: Aspectos Bioćticos”, Anais da ANPAP, 2007.
}

Temáticas, Campinas, 18(35/36): 173-192, jan./dez. 2010 
Karen Warren elabora o conceito de uma ética ecofeminista que critica a dupla dominação da mulher e da natureza no discurso patriarcal, propondo uma nova forma de se relacionar com a natureza não-humana, uma ćtica baseada numa postura humana de cuidar e nutrir. Warren argumenta que:

Uma ética ccofeminista é tanto uma crítica da dominação masculina das mulheres e da natureza, quanto uma tentativa de criar uma ética livre de uma associação $\mathrm{cm}$ termos de gênero entre a mulher c a natureza. Ela não apenas reconhece as múltiplas vozes de mulheres localizadas diferentemente por raça, classe social, idade, e considerações étnicas, cla centraliza estas vozes. Ecofeminismo clabora nas múltiplas perspectivas daquelas que são tipicamente omitidas e desvalorizadas em discursos dominantes, por exemplo, as mulheres ligadas ao movimento Chipko, desenvolvendo uma perspectiva global sobre o papel da dominação masculina na exploração da mulher e da natureza. Uma perspectiva ecofeminista é, portanto, estruturalmente pluralista, inclusiva, contextualista, enfatizando através de exemplos concretos o papel crucial que o contexto cumpre na comprcensão de práticas sexistas e naturistas. (Warren, in Merchant, 2005, p. 195-6)

Merchant obscrva que uma ética ecofeminista baseada no amor, cuidado e confiança é criticada por algumas feministas como tendendo a um essencialismo que reforçaria construções sociais nas quais a mulher seria $\mathrm{em}$ e.ssência mais emotiva, carinhosa e acolhedora que o homem (Ibid, p. 196). Val Plumwood examina essa crítica por parte de muitas feministas contra a ênfase ecofeminista dada à associação da mulher com a natureza. Algumas feministas alegam que, ao abraçar a causa ambiental, o argumento ecofeminista estaria reforçando a dicotomia mulher-natureza $\mathrm{X}$ homem-cultura, que fundamenta a lógica opressiva do patriarcado. Plumwood investiga a crítica mordaz de algumas feministas contra o ecofeminismo:

A própria idéia da conexão da mulher com a natureza parece ser, para muitas, regressiva e um insulto, promovendo 
imagens da mulher como mãc naturcza, como passiva, animal reprodutivo, vaca contente imersa no corpo $\mathrm{c}$ na expcriência não-reflexiva da vida. (Plumwood, 1993, p.20).

Por outro lado, Plumwood acredita que a questão ambiental deveria ser central para of feminismo contemporâneo, porque, se o objetivo da mulher for pertencer a um modelo de humanidade que se iguala ao homem branco de elite, assumindo assim uma posição numa classe privilegiada que exclui $\mathrm{e}$ domina a natureza não-humana, esta nova posição seria também moralmente problemática. Plumwood argumenta que, mesmo se esta absorção das mulheres num modelo "master" de cultura humana fosse bem sucedida, isto apenas levaria à ampliação de uma classe dominante pela participação de algumas mulheres, não representando um questionamento da lógica da dominação. Como Plumwood coloca:

A crítica aqui é que o aparato conceitual relacionado a ordens superiores $\mathrm{c}$ inferiores permanece intacto $\mathrm{e}$ inquestionado; o que é alcançado é o alargamento da classe dominante, scm que a base da própria dominação seja questionada. E a tentativa de simplesmente aumentar a classe privilegiada, ao estendê-la para incluir algumas mulheres, não apenas ignora uma dimensão moral crucial do problema; ela também ignora a maneira como diferentes tipos de dominação agem como modelos, apoio e reforço, um após o outro, c a maneira como a mesma estrutura conccitual de dominação reaparece em muitos diferentes grupos inferiorizados: como temos visto, cla marca as mulheres, a natureza, povos "primitivos", escravos, animais, trabalhadores braçais, "selvagens", pessoas de cor, todos que supostamente scriam "próximos aos animais". (Ibid., p.29)

Portanto, autoras ecofeministas ampliam a crítica à lógica da dominação para examinar a relação humana com a natureza não-humana. Entretanto, o campo dos debates ecofeministas não é homogêneo, pois surgiram diversas 
vertentes ao longo das décadas de discussões. Carolyn Merchant identifica as seguintes tendências: ecofeminismo liberal; ecofeminismo cultural; ccofeminismo social; c ecofeminismo socialista. (Merchant, idem, pp.200-209).

O ecofeminismo liberal se concentra na luta pela igualdade entre mulheres $\mathrm{c}$ homens, sem, contudo, questionar a lógica capitalista. Esta vertente estaria vinculada ao feminismo liberal, também conhecido como feminismo de primeira onda ou histórico (do séc. XVII até a década de sessenta do século passado), e ainda ao feminismo de igualdade a-crítica (feminism of uncritical equality), por buscar ajustar a mulher ao padrão de vida masculino c ao modelo masculino de humanidade e cultura que era apresentado como neutro em termos de gênero (Plumwood, idem, p. 27). A atuação de ecofeministas liberais se dá principalmente no nível da legislação, em prol de um maior controle dos níveis de poluição e da criação de mecanismos de proteção $\mathrm{e}$ conservação ambiental.

Segundo Merchant, a perspectiva do ecofeminismo cultural se desenvolveu entre as décadas de sessenta e setenta, com a segunda onda do feminismo. Essa abordagem desafia a desvalorização tanto da mulher quanto da natureza na cultura ocidental, assumindo uma postura crítica em relação à ciência e à tecnologia, voltando-se para a celebração de antigos rituais. Ecofeministas culturais buscaram na simbologia da deusa uma maneira de atribuição de poder, de valorização do corpo feminino e de sua capacidade reprodutiva. Críticas ao ecofeminismo cultural apontam para a visão essencialista do homem e da mulher, que estaria além da cultura e socialização. Nessa abordagem, estaria implícita a ideia de que "o que os homens fazem para o planeta é ruim; o que as mulheres fazem é bom" (Merchant, idem, p. 204). E ainda mais importante, o ecofeminismo cultural não faz uma crítica ao sistema capitalista, ao problema da pobreza e do racismo e, por isso, parece não desenvolver estratégias para mudanças estruturais na sociedade (Prentice, Susan, in Merchant, idem, p. 204).

Em contraste com as vertentes liberal e cultural do ecofeminismo, as perspectivas do ecofeminismo social e socialista fazem uma crítica ao capitalismo e ao patriarcado, identificando a necessidade de transformar essas estruturas para que se possam libertar tanto as mulheres quanto a natureza, 
como demonstra Merchant. Estas abordagens se fundamentam em ideias marxistas de produção c reprodução. Segundo Janet Biehl, o ecofeminismo social supõe que a ideia de dominação da natureza parte da dominação de humanos por humanos, c que a mancira de se chegar a uma sociedade ecológica seria acabar com todas as formas de dominação (Biehl in Merchant, idem, pp. 205-206).

No ecofeminismo socialista, há uma ênfasc na questão da reprodução da vida tanto humana quanto não-humana, focando no problema da fome, poluição do solo, ar e água, extinção de espécies c sobrevivência de uma maneira geral. Compreende-se que, para o desenvolvimento humano, os aspectos sócio-econômicos estejam diretamente ligados à questão da qualidade de vida tanto da comunidade quanto da conservação ambiental.

As perspectivas ecofeministas social e socialista parecem ser especialmente importantes nos países em desenvolvimento, onde um grande número de mulheres, homens, crianças e idosos em situação de risco social vive as dramáticas consequências do capitalismo global. É justamente nesses países que se pode observar a necessidade e o impacto positivo da efetiva ação de mulheres de luta (auto-denominadas ou não feministas ou ecofeminstas). A fisica, ativista ambiental e ecofeminista Vandana Shiva é um dos nomes mais respeitados no cenário internacional, por sua luta contra os efeitos da globalização e da cconomia neoliberal nos países $\mathrm{em}$ desenvolvimento. $\mathrm{Na}$ década de 1970, participou do "Movimento das Mulheres de Chipko", formado em sua maioria por mulheres que adotaram a tática de se amarrar às árvores para impedir sua derrubada e o despejo de lixo atômico na região. Shiva fala sobre os princípios que fundamentaram esse movimento:

Na Índia hoje, há dois paradigmas de manejo florestal um valorizador da vida (life-enhancing) e um destruidor da vida (life-destroying). O paradigma valorizador da vida emerge da floresta $\mathrm{c}$ do princípio feminino; o paradigma destruidor da vida emerge da indústria c do mercado... Pois a maximização do lucro é consequência da destruição das condições de renovação, os dois paradigmas são 
cognitivamente e ecologicamente incomensuráveis. $O$ primeiro paradigma surgiu da cultura antiga da floresta indiana, em toda sua diversidade, e está sendo renovada nos tempos contemporâneos pelas mulheres de Garhwal através do Chipko. (Shiva, in Merchant, idem, 214).

Na década de oitenta, Shiva abandonou uma carreira acadêmica como fisica para fundar o Research Foundation for Science, Teclonology and Ecology, afirmando ter sido sua participação no "Movimento das Mulheres de Chipko" sua principal escola:

Meu envolvimento com o "Movimento das Mulheres de Chipko", sobre o qual escrevi extensivamente em Staying Alive (Permanecendo Viva), ensinou-me que os desprovidos de poder não o têm, não por falta de conhecimento, mas por causa da apropriação de scus recursos pelos poderosos. Frequentemente chamo Chipko de minha Universidade de Ecologia e as mulheres de Chipko minhas professoras, mesmo que elas nunca tenham ido a uma escola e eu tenha um doutorado $\mathrm{cm}$ Teoria Quântica. Aprendi na década de setenta que educação formal não é um requisito para o conhecimento, e que tribos comuns, camponeses e mulheres têm uma experiência ecológica tremenda. Eles são experts em biodiversidade, experts em sementes, e experts $\mathrm{cm}$ água. A cegueira dos sistemas dominantes ao seu conhecimento c a sua expertise não é prova da ignorância dos pobres e sem poder. É, de fato, prova da ignorância dos ricos e poderosos. ${ }^{3}$

Nesta passagem, pode-se perceber como as questões ambientais estão entrelaçadas às questões sociais, de gênero, classe, raça, e também às relações entre os hemisférios Norte e Sul, na atuação ecofeminista de Shiva. A engenharia genética e a indústria biotecnológica são também alvos de uma crítica radical por parte de Shiva, chamada de "Segunda Revolução Verde", que, como a

\footnotetext{
${ }^{3}$ Shiva, Vandana, The Practice of Earth Democracy. Disponivel em http://wwwnavdanya.org/ about/practice_carth_dem.htm, acessado cm 04/02/2009.
} 
primeira, ameaça a vida de milhares de pequenos trabalhadores rurais no mundo todo.

Como no trabalho ativista de Shiva, ecofeministas $\mathrm{cm}$ muitos países em desenvolvimento têm se voltado para as questões ambientais em comunidades socialmente marginalizadas. No Brasil, o ccofeminismo também tem fornecido subsídios teóricos, desdobrando-se em ações práticas para um trabalho de valorização de mulheres em assentamentos rurais, como nos relata Naia Oliveira, em um artigo sobre sua experiência com os grupos Mulheres da Terra, no Assentamento Projeto Viamão (RS), do Instituto Nacional de Colonização e Reforma Agrária (INCRA). ${ }^{+}$Oliveira buscou referências no ecofeminismo e na metodologia da alfabetização ccológica para seu trabalho, cujo foco reunia a questão de gênero e a ambiental. Segundo Oliveira, seu trabalho (realizado em 2002-3) foi instigado pela baixa participação das mulheres nas discussões que envolviam as decisões sobre a formulação de um plano de desenvolvimento no Assentamento e a necessidade de preservação do ecossistema local. Vemos aqui como os preceitos de uma ética ccofeminista têm se traduzido em ações reais que poderão trazer mudanças concretas em comunidades que buscam se reestruturar.

Para Edvalda Pereira Torres Lins Aroucha, ecopedagoga, educadora agroecológica, coordenadora geral da ONG AGENDHA - Assessoria $\mathrm{c}$ Gestão em Estudos da Natureza, Desenvolvimento Humano e Agroccologia, o ecofeminismo oferece uma perspectiva abrangente para enfrentarmos a grande problemática sócio-ambiental atual:

O Ecofeminismo como a referência mais objetiva c pragmática de formulação e de luta pelo Desenvolvimento Sustentável e Socioambiental, tem a inspiração maior c, por ter, também, a maior quantidade de naturais representantes $\mathrm{cm}$ termos populacionais, tem em si a mais significativa e significante força intrínseca, deve buscar,

\footnotetext{
4 Oliveira, Naia. Ecofeminismo, Alfabetização ccológica e assentamento sustentável. Disponivel cm http://www.fazendogenero7.ufsc.br/artigos/N/Naia_Oliveira_31.pdf, acessado em 04/02/2009.
} 
portanto, congregar todas as construções sociais proativas, não para repetir o erro histórico da subjugação das outras forças do sentir e saber humano, como o que foi feito historicamente pelo poder patriarcal e scu capitalismo econômico, ambiental, bélico e político -, e sim para estabelecer as bases c as práticas eco-sociais dos direitos humanos e da cidadania plena para todas as Mulheres e Homens de todas as Idades, Etnias, Raças, Religiões, Biomas, Nações e Culturas do nosso Planeta/Mulher, Mãe Terra. ${ }^{5}$

Portanto, para Aroucha e muitas ecofeministas, esta ética não se restringe a mulheres exclusivamente (apesar de ter a emancipação feminina como um objetivo central), mas se traduz numa luta radical contra a lógica da dominação.

Ao examinar, mesmo que sinteticamente, alguns pontos relevantes das discussões ccofeministas contemporâneas, pode-se concluir que, na prática, o ecofeminismo contribui efetivamente para a luta em prol da emancipação da mulher e de outros grupos historicamente segregados, bem como para a defesa do meio ambiente, mesmo considerando as divergências conceituais de cada vertente. A questão do essencialismo no discurso ecofeminista cultural realmente parece ter levado a um desvio de atenção das questões mais estruturais que afligem a vida de milhares de seres humanos e não-humanos no planeta. Portanto, gostaria de transpor os parâmetros dos ecofeminismos social e socialista para o campo das artes visuais, mais especificamente para a análise de projetos que lidam com a questão ambiental, tendo como foco a relação humana com animais. Esta escolha se justifica por sua maior amplitude em relação às outras vertentes do ecofeminismo, abarcando questões de classe, gênero, etnia, ambientais, como exposto acima, oferecendo instrumentos críticos que poderão ser úteis nas discussões sobre arte, ciência e natureza, que serão tratadas em seguida.

\footnotetext{
5 Aroucha, Edvalda Percira Torres Lins. "Ecofeminismo e Descnvolvimento Sustentável c Socioambiental". Disponivel cm http://74.125.47.132/search?q=cache:o5iyf Azw0Ls]: www.agendha.org.br/arquivos/ccofeminismo.pdf + cofeminismo\&hl=ptBR\&ct $=\operatorname{clnk\& cd}=9 \& g l=b r \& c l i e n t=$ fircfox-a, acessado $\mathrm{cm} \mathrm{04/02/2009}$.
} 


\section{A ARTE CONTEMPORÂNEA E O MEIO AMBIENTE}

No cenário arústico internacional, desde a década de sessenta, observase o aparecimento de preocupações ambientais no trabalho de artistas hojc já consagrados, como Joseph Beuys, Hans Haackc, Helen e Newton Harrison, entre muitos outros. Estes artistas são considerados pioneiros de uma arte voltada para a problemática ambiental, e servem de refcrência e inspiração para muitos artistas que os sucederam.

A colaboração com cientistas, ambientalistas e urbanistas tem se tornado cada vez mais comum na prática artística contemporânea que lida com a temática da natureza. Além deste enfoque às vezes trans-, inter - ou multidisciplinar entre artistas e uma grande variedade de outros profissionais, observa-se também o surgimento de um certo tipo de "colaboração" com animais em projetos artísticos. Considera-se aqui como "colaborativa" a participação ativa de animais vivos no desenvolvimento de obras artísticas.

Talvez a obra mais amplamente conhecida scja a histórica performance do artista conceitual alemão Joseph Beuys intitulada I L ike America and America Likes me ("Eu Amo a América e a América me Ama"), na qual Beuys conviveu com um coiote durante cinco dias e cinco noites, em uma sala da galeria René Block, em New York, em 1974. Essa, como a obra de Beuys como um todo, tem um caráter fortemente político, social, ecológico e metafísico.

Essa performance, extensivamente documentada, iniciou com a chegada de Beuys na galeria, envolto em um cobertor de feltro, tendo sido transportado em uma ambulância coberta com cruzes vermelhas e sinalização de "emergência".

O emblemático encontro com o coiote nos Estados Unidos da América reflete claramente o desejo de Beuys de dialogar com valores nativos que são ameaçados pela cultura mecanicista $\mathrm{e}$ materialista ocidental (representada pela pilha de exemplares do Wall Street Journal entregues diariamente no espaço da performance na galeria). Scgundo David Levi Strauss, o coiote representa tanto no nível simbólico quanto biológico a grande capacidade de sobrevivência, 
estando associado com o conhecimento shamânico nativo como uma possivel forma de conhecimento paralelo ao conhecimento racional ocidental. ${ }^{6}$

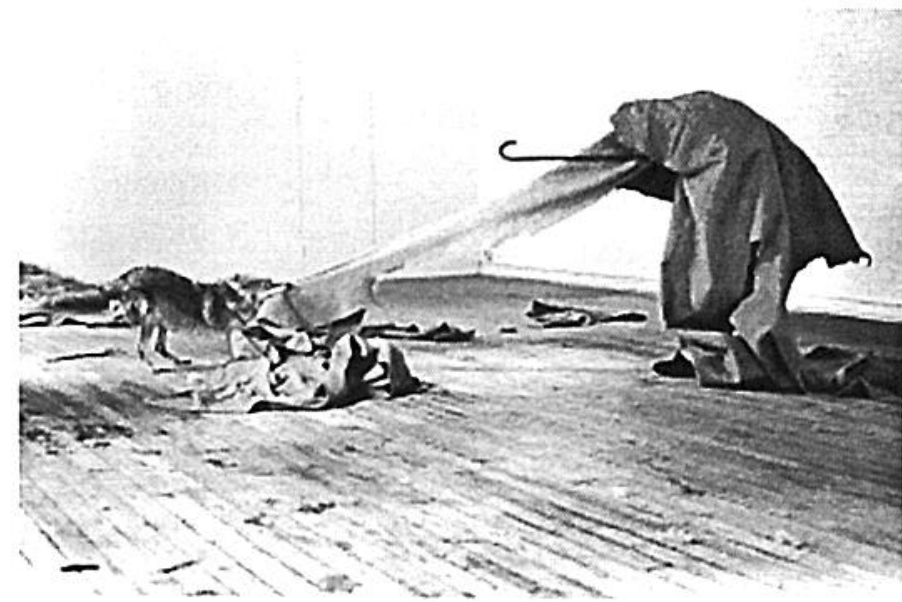

Joseph Beuys, I Like America and America Likes me Galcria René Block, New York, cm 1974.

Pode-se alinhar a ação de Beuys com preceitos de uma ética ecofeminista, pois ambos fazem uma crítica à dominação da natureza e dos povos nativos pela sociedade capitalista patriarcal europeia, que se impôs de maneira violenta no novo continente no processo de colonização. Beuys busca um diálogo com esta América subjugada, fazendo assim uma crítica estrutural do sistema econômico e cultural que domina e oprime as culturas nativas e natureza.

Anteriores a essa performance de Beuys com o coiote americano, e também muito importantes, foram as performances do artista grego Jannis Kounellis com pássaros vivos em 1967, e sua célebre instalação com doze cavalos vivos dentro da Galeria L'Attico em Roma, em 1969. O significado

\footnotetext{
'Strauss, David Levi, Between dog \& wolf, Essays on Art and Politics, Autonomedia, Brooklyn, NY, 1999. Disponível em http://www.bockleygallery.com/css/american_bcuys.html, accssado cm 04/02/2009.
} 


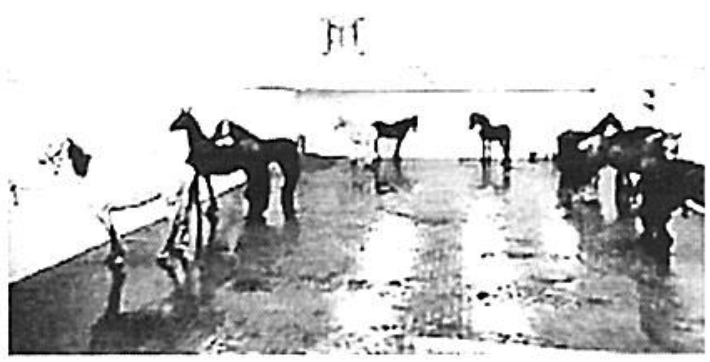

Jannis Kouncllis, instalação com do\%c cavalos Galeria L'Attico, Roma, 1969. da obra parece emergir da dicotomia entre a cultura e a natureza: a realidade biológica do animal vivo dentro da galeria contrasta com seu significado cultural e pictórico do cavalo associado a virtudes heróicas,

de bravura e virilidade.

Kounellis (juntamente com Michelangelo Pistoletto, Giovanni Anselmo, Giuseppe Penone, Giulio Paolini, Mario Merz, Luciano Fabro, e Gilberto Zorio) foi um dos fundadores do movimento de neo-vanguarda italiano Arte Povera, que surgiu no clima politizado da década de sessenta. A Arte Povera fazia uso de materiais nãoconvencionais (terra, madeira e trapos), considerados "pobres", com o objetivo de dissolver a barreira entre a arte c o cotidiano, ou seja, fazendo assim uma ponte com o aspecto anti-arte subversivo das vanguardas históricas. Pode-se dizer também que a Arte Povera lida com a problemática da natureza na sociedade industrial, por esse uso de materiais orgânicos na produção de muitas obras.

Apesar da participação ativa de animais nas performances acima, talvez a relação artística de caráter colaborativo mais longa entre animal e humano na arte contemporânea seja a parceria de doze anos entre o artista norteamericano William Wegman e seu cachorro Man Ray. Desde a década de setenta, Wegman e Man Ray produziram séries de performances documentadas em vídeo, e na década de oitenta a parceria cresceu com a chegada da cadela Fay Ray, e posteriormente de seus filhotes. Além do vídeo e da performance, Wegman passou a trabalhar com fotografia, cuja temática retrata com humor seus cachorros. Talvez seu trabalho mais conhecido seja o divertido vídeo Dog Duet (1975,) com Man Ray e outro cachorro, que observam atentamente e acompanham com a cabeça o movimento de um objeto que o artista movimenta em frente à câmera. 
Estas performances históricas com a participação de animais diferem em objetivos c cada uma apresenta contextos e especificidades próprias. Entretanto, pode-se dizer que a atitude do artista em relação ao animal nestes projetos seria de parceria, muito diferente da abordagem mecanicista, na qual o animal não-humano é tomado como um mero objeto passível de estudo e experimentação para o benefício da humanidade. Os projetos de Kounellis e Wegman não apresentam uma atitude opressora em relação aos animais utilizados nos processos artísticos, que cstariam alinhados a uma ética ecofeminista de maneira geral. Entretanto, é possível traçar paralelos mais diretos entre estes projetos e a perspectiva social/socialista do ecofeminismo, pois, nestes projetos, o animal é usado principalmente para simbolizar significados culturais, estando as conotações ecológicas e sociais menos evidentes.

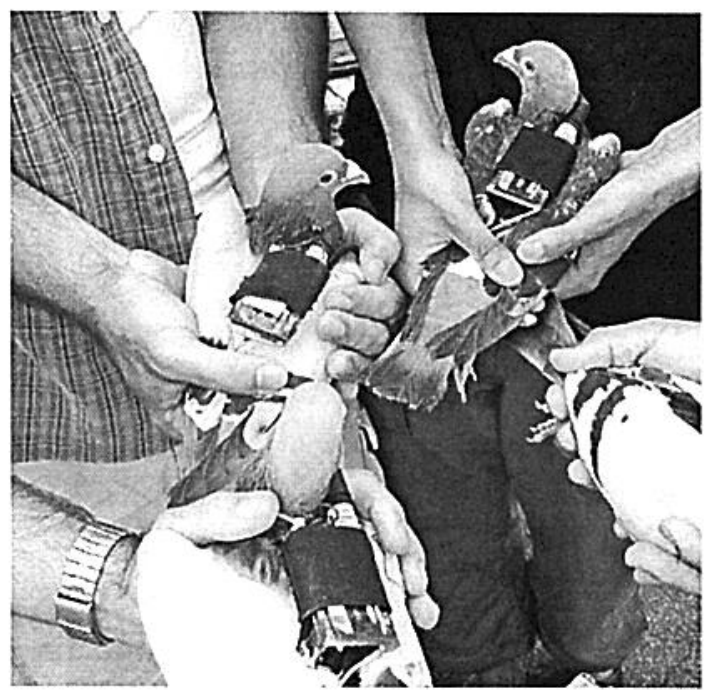

Beatriz da Costa, com pombos com equipamentos Projeto PigconBlog, 2006

No projeto artístico PigeonBlog (2006) desenvolvido por Beatriz Costa et. cols, pode-se observar mais claramente como o animal colabora com a artista e um aparato tecnológico para a produção de uma arte com forte caráter eco-ativista, que inclui preocupações sociais. O projeto equipa pombos- 
correio com GPS c sensores eletrônicos para medir a poluição atmosférica, e equipamentos capazes de transmitir a informação coletada em tempo real para o PigeonBlog, ficando disponível online para o público. Segundo a artista, "O Pigeonblog é um experimento social entre animais humanos e não humanos", cujos resultados coletados também seriam úteis para a comunidade científica.

A artista conta que a ideia do projeto surgiu de uma fotografia de um pombo carregando uma câmera no pescoço para fins de espionagem militar. Foi justamente este uso de animais com tecnologia de vigilância que instigou a artista a subverter o uso de tecnologias atuais de vigilância para fins ecoativistas. Beatriz da Costa compartilha com ccofeministas preocupações sobre a qualidade do ar e o impacto da poluição na saúde das pessoas e no meio ambiente, pois para ela:

PigeonBlog adota uma maneira lúdica de abordar tópicos muito sérios: 1) A perigosa poluição atmosférica continua a afetar as vidas e o desenvolvimento de crianças crescendo $\mathrm{cm}$ zonas urbanas, e resulta $\mathrm{em}$ uma significativa causa $\mathrm{de}$ mortalidade $\mathrm{cm}$ Los Angeles e cm outras comunidades urbanas 2) fábricas que emitem perigosos gases poluentes para o ar são localizadas em áreas de baixa renda, colocando assim o risco de problemas de saúde em setores sociais já $\mathrm{cm}$ desvantagens, que não dispõem de recursos para se defender destas práticas. ${ }^{7}$

Neste projeto a artista se alia ao animal, incorporando novas tecnologias para criar meios independentes de coleta de informações sobre a qualidade do ar. Desta forma, a obra de arte promove acesso, em primcira mão, a informações ambientais importantes para a comunidade civil sem a intermediação de órgãos governamentais que poderiam manipular dados para fins políticos ou econômicos. Aqui se observam mais fortemente aspectos de uma prática alinhada a uma ética ecofeminista, pela preocupação da artista

7 Beatriz da Costa, l'igconBlog. Disponivel em http://www.pigconblog.mapyourcity.net/ statement.php, accssado em 04/02/2009.

Temáticas, Campinas, 18(35/36): 173-192, jan./dez. 2010 
com sérios problemas ambientais que afligem a todos, mas prejudicam mais diretamente as comunidades mais carentes.

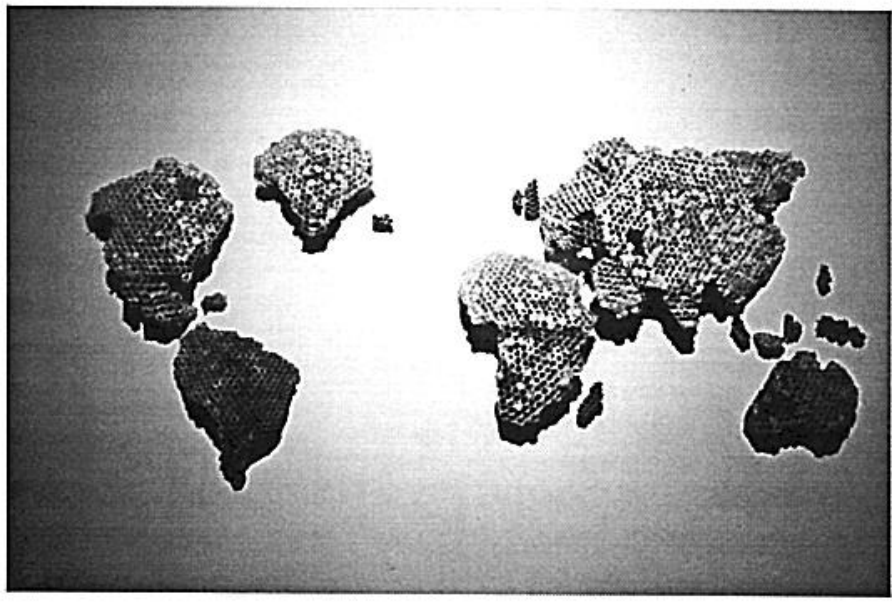

Silvana c Frederico Macedo, Cooperari, 2007

Finalmente, vamos nos voltar para a vídeo-instalação sonora intitulada Cooperari: o relicário mágico do imprevisto (2007), desenvolvida por Silvana Macêdo em parceria com o músico Frederico Macêdo e com marimbondos. Uma sequência de imagens de marimbondos registrada em vídeo mostra a construção de um ninho, que é projetado sobre um canto de uma das paredes do espaço expositivo. Justaposto à projeção, está montado um mapa-mundi feito de casinhas de marimbondos abandonadas. Um sistema de som surround com uma composição eletro-acústica integra a composição do trabalho, juntamente com o seguinte texto: competição cooperação.

A ideia inicial em torno da elaboração de Cooperari vem de uma reflexão sobre a dinâmica (dialética) entre a cultura e a natureza. De fato, nenhum termo desta dicotomia cultura/natureza pode ser dissociado do outro, ambos constituem e são constituídos mutuamente. Insetos sociais como centro da obra oferecem um rico campo para se estudar como nossos contextos culturais interferem na maneira como interpretamos o comportamento animal. Como 
no ecofeminismo, a obra lida com a dialética entre a realidade biológica e as construções sociais produzidas pela cultura em torno dela. Há uma crítica implícita aos preceitos da sociobiologia, que buscam na biologia explicações para o comportamento humano. Cooperari se estrutura de maneira contrária à da teoria do gene egoísta (selfish gene) e da teoria darvinista "da lei do mais forte", que foram usadas para justificar o individualismo capitalista como um sistema natural, ou seja, ideologicamente colocando a questão da dominação do humano pelo humano e da natureza pelo humano como uma coisa aceitável, inevitável e biologicamente determinada. Ao invés de usar o princípio da competição como o maior determinante evolutivo, Cooperari coloca $\mathrm{cm}$ evidência o aspecto da cooperação também presente na natureza e no comportamento animal. Desta forma, a obra retira a ênfase (ideológica) dada à competição como a única verdade biológica, que justificaria o egoísmo social presente no capitalismo. Cooperari demonstra a base ideológica dos discursos que naturalizam uma realidade socialmente construída para o benefício de uma elite humana, assim como o ecofeminismo desconstrói o conceito do feminino formulado pela ideologia patriarcal, que naturaliza tal conceito, que na realidade foi construído historicamente c culturalmente com a finalidade de oprimir a mulher.

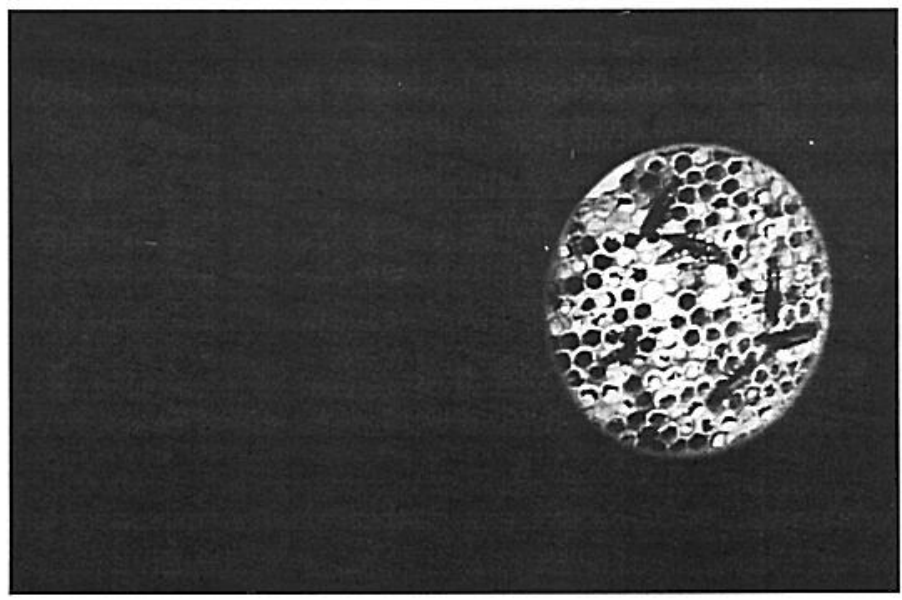

Silvana e I'rederico Macedo, Cooperari, 2007.

Temáticas, Campinas, 18(35/36): 173-192, jan./dez. 2010 
O aspecto da cooperação é também refletido na participação do animal na construção da obra, pois a artista não constrói seu mapa-mundi sozinha, mas se apropria de ninhos feitos pelos insetos para compor seu novo projeto de mundo. A prática colaborativa nas artes visuais representa um movimento contra o mito romântico do artista como um gênio individual (historicamente identificado com o homem branco europeu); portanto, a colaboração com o músico Frederico Macedo já socializa o processo de produção artística. Esta colaboração, quando incorpora a ação do animal, cria um espaço privilegiado para a reflexão sobre a importância do trabalho muitas vezes não percebido, mas primordial, dos invertebrados na base do ecossistema planetário. A própria construção do ninho se dá de forma colaborativa pelos insetos, pois o marimbondo não trabalha de forma solitária.

\section{CONSIDERAÇÕES FINAIS}

Opresente estudo buscou conceitos filosóficos, debates políticos c vertentes relevantes no campo do ecofeminismo para examinar trabalhos artísticos que lidam com a participação de animais vivos, aproximando a ação dos artistas aos preceitos de uma ética ecofeminista. Mesmo que os artistas não tenham adotado apriori uma abordagem ecofeminista, é possivel usar os preceitos do ecofeminismo para analisar criticamente a atitude humana em relação aos animais, traduzida nos projetos artísticos considerados neste artigo.

A discussão sobre o essencialismo dentro do campo do ecofeminismo é sem dúvida revelante, pois nos parece importante redirecionar o foco do ecofeminismo para uma crítica da lógica da dominação tanto da mulher quanto da natureza pela razão instrumental no discurso patriarcal, ao invés de reforçar uma ligação mítica da mulher com a natureza, com o risco de cair $\mathrm{em}$ clichês ideologicamente suspeitos. Além disso, uma abordagem centrada exclusivamente na relação feminina com a natureza excluiria o trabalho de muitos artistas do gênero masculino que foram $\mathrm{c}$ são importantes ativistas ecológicos, cuja obra tem propiciado importantes reflexões sobre a relação humana com o meio ambiente. É justamente através da visão mais ampla do 
ecofeminismo social e socialista que se pode traçar uma ética ccofeminista que dê conta da complexidade dos problemas sócio-ambientais atuais, para os quais alguns artistas contemporâneos se voltam.

Nos exemplos escolhidos, os artistas trabalharam de forma colaborativa com os animais vivos, com maior ou menor grau de engajamento em questões ecológicas ou ativistas, mas todos apresentaram uma conduta ética que não colocou em risco a integridade dos animais envolvidos, enfatizando a relação humana pacífica ou não-violenta. Nestes projetos colaborativos com os animais, mesmo que estes não tenham escolhido participar (o que poderia caracterizar uma relação utilitária do artista para scus fins artísticos), a relação estabelecida com eles está longe de ser comparável com a submissão e exploração de animais para força física, experimentação científica e consumo humano. No contexto artístico, o animal participa do processo poético com o artista, tendo sua integridade fisica e possivelmente psicológica respeitada, não caracterizando uma relação de domínio como em outros contextos.

Em trabalhos futuros, podem-se abordar obras artísticas que vão contra as premissas da ética ecofeminista, pois o campo da arte contemporânea também abarca trabalhos controversos que envolvem o sofrimento, a manipulação genética e até mesmo a morte de animais. Acredita-se que a ética ecofeminista possa elucidar a problemática moral por trás deste tipo de atitude $\mathrm{em}$ relação à natureza não-humana.

\section{AGRADECIMENTOS}

Agradeço a UDESC - Universidade do Estado de Santa Catarina pelo apoio institucional a esta pesquisa.

ABSTRACT: This article investigates human interaction with other animals and examines
its representation or presentation in contemporary art, considering ethical issues involved
in this process. The Ecofeminist perspective is proposed as a critical tool to analyse artworks
that deal with animals. Within this ecofeminist approach, the works by the artists: Joseph 
Beuys, Jannis Kounnellis, Wiliam Wegman and Beatriz da Costa are discussed. It is also considered the video installation Cooperari, by Silvana \& Frederico Macêdo, produced in the context of this study.

KEYWORDS: Ecofeminism, contemporary art, animal.

\section{REFERÊNCIAS BIBLIOGRÁFICAS}

AROUCHA, Edvalda Pereim Torres Lins. "Ecofeminismo e Desenvolvimento Sustentável e Socioambiental". Disponivel cm

http://74.125.47.132/search?q=cache:o5iyfAzw0Lsj:www.agendha.org.br/ arquivos / ecofeminismo.pdf + ecofeminismo\&hl $=\mathrm{pt}$ BR\&ct $=$ clnk\&cd $=9 \& g l=$ br\&client $=$ firefox-a, acessado $\mathrm{em} \mathrm{04/02/2009.}$

COSTA, Beatriz. PigeonBlog, disponivel no website http://www.pigeonblog.mapyourcity.net/statement.php acessado em 04/02/2009.

MERCHANT, Carolyn. Radical Ecology: the search for a liveable world. 2. Ed. New York e Londres: Routledge, 2005.

OLIVEIRA, Naia. "Ecofeminismo, Alfabetização ecológica e assentamento sustentável". Disponivel em http://wwww.fazendogenero7.ufsc.br/ artigos/N/Naia_Oliveira_31.pdf, site acessado em 04/02/2009.

PLUMWOOD, Val. Feminism and the Mastery of Nature: Feminism for Today. Londres: Routledge, 1993.

SHIVA, Vandana. \& MIES, Maria. Ecofeminism. Zed Books, 1993. . "The Practice of Earth Democracy", disponivel em

http://www.navdanya.org/about/practice_earth_dem.htm, acessado em 04/02/2009. 
STRAUSS, David Levi, "Between dog \& wolf, Essays on Art and Politics", Autonomedia, Brooklyn, NY, 1999, disponível em, http://wwww.bockleygallery.com/css/american_bcuys.html, website acessado em 04/02/2009.

WARREN, Karen (ed.). Ecological Feminism. London:Routledge, 1994. 